\title{
The distribution of distinct integrins in focal contacts is determined by the
}

\section{substratum composition}

\author{
KARL R. FATH ${ }^{1}$, CORA-JEAN S. EDGELL ${ }^{2}$ and KEITH BURRIDGE ${ }^{1}$ \\ ${ }^{1}$ Department of Cell Biology and Anatomy and ${ }^{2}$ Pathology Department, The University of North Carolina at Chapel Hill, Chapel Hill, NC 27599, \\ USA
}

\begin{abstract}
Summary
The distribution of two integrins, the fibronectin receptor and the vitronectin receptor, has been explored in an endothelium-derived cell line plated onto various substrata. On a fibronectin substratum, in the presence of serum, these cells develop focal contacts that contain the fibronectin receptor, whereas the vitronectin receptor is diffusely distributed over the cell surface. Conversely, cells plated onto vitronectin-coated coverslips concentrate only the vitronectin receptor within focal contacts. The accumulation of the vitronectin receptor within focal contacts also occurs when the cells are plated on uncoated coverslips but in the presence of serum. Therefore, we conclude that under normal culture conditions (i.e. in serumcontaining media), the vitronectin receptor is the predominant form of integrin involved in substratum adhesion. This conclusion is supported by experiments in which cells were cultured on fibronectin-coated coverslips in the presence of serum.
\end{abstract}

Initially these cells developed focal contacts containing only the fibronectin receptor. Within several hours, however, there was a progressive replacement of focal contacts containing the fibronectin receptor by focal contacts expressing the vitronectin receptor. After approximately $12 \mathrm{~h}$ in culture, most cells contained focal contacts expressing only the vitronectin receptor.

Focal contacts containing either the fibronectin or vitronectin receptor were both associated with the termini of stress fibres and contained the proteins talin and vinculin. These observations lead us to propose that the cell does not discriminate between these different integrins when assembling the cytoskeletal components at the cytoplasmic face of focal contacts.

Key words: extracellular matrix, fibronectin receptor, talin, vitronectin receptor.

\section{Introduction}

Many cultured cells form specialized adhesions to the underlying substratum, known as focal contacts, adhesion plaques or focal adhesions (reviewed by Burridge, 1986; Burridge et al. 1988; Woods \& Couchman, 1988). At the focal contact, the extracellular face of the plasma membrane is separated from the substratum by $10-15 \mathrm{~nm}$ (Izzard \& Lochner, 1976), and the cytoplasmic face anchors actin microfilament bundles (stress fibres). The formation of focal contacts requires the adsorption of extracellular matrix (ECM) proteins such as fibronectin $(\mathrm{FN})$ or vitronectin (VN) to the substratum. Although substratum-bound $\mathrm{FN}$ promotes the formation of focal contacts (Couchman et al. 1982; Woods et al. 1986), cells in normal culture conditions clear the $\mathrm{FN}$ from the adhesions as a result of their traction on the substratum (Avnur \& Geiger, 1981; Grinnell, 1986). The cleared FN is assembled into fibrils, which move on the cell surface towards the nucleus (Avnur \& Geiger, 1981). This clearance requires serum or other proteins in the media because cells plated in serum-free (or low serum concentrations) media do not remove FN from focal contacts (Grinnell, 1986).

In contrast to $\mathrm{FN}$, the relationship of VN (serum spreading factor) to focal contact formation has been studied in less detail. This serum component promotes cell adhesion and adsorbs very tightly to glass (Hayman et $a l .1985 b)$. When cells are grown on glass coverslips in serum-containing media, VN coats the coverslips but, unlike $\mathrm{FN}$, it is not cleared by cells (Baetscher et al. 1986; Neyfakh et al. 1983). Although VN promotes adhesion, it is evenly spread on the substratum and is not concentrated beneath focal contacts. Detection of VN beneath focal contacts by immunofluorescence microscopy requires permeabilization or detachment of the cells due to its inaccessibility to antibodies (Baetscher et al. 1986; Neyfakh et al. 1983). Because it is not cleared from focal contacts, we have suggested that VN may be more important than FN for the formation of focal 
contacts by many cells grown in the presence of serum (Burridge et al. 1988).

The integrin family of cell surface receptors for ECM proteins, such as $\mathrm{FN}$ and $\mathrm{VN}$, has recently received considerable attention (reviewed by Buck \& Horwitz, 1987a; Hynes, 1987; Ruoslahti \& Pierschbacher, 1987). Integrins are concentrated within focal contacts (Chen $e t$ al. 1985; Damsky et al. 1985; Giancotti et al. 1986; Kelly et al. 1987; Marcantonio \& Hynes, 1988) and provide a potential transmembrane link between the ECM and cytoskeletal proteins such as talin (Horwitz et al. 1986). The binding of integrins to their ECM ligands is disrupted by some specific antibodies (Brown \& Juliano, 1985; Chen et al. 1985; Cheresh, 1987; Greve \& Gottlieb, 1982; Neff et al. 1982) and peptides (Hayman et al. 1985a; Pierschbacher et al. 1983; Yamada \& Kennedy, 1987). These agents also disrupt focal contacts, indicating the importance of the integrin ECM receptors in formation and maintenance of these adhesions.

Whereas avian cells apparently contain an integrin that binds to both FN and VN (Buck \& Horwitz, 1987b), mammalian cells express distinct integrins for these two ECM components (see, e.g., Hynes, 1987; Ruoslahti \& Pierschbacher, 1987). Antibodies specific for the FN receptor (FNR) or VN receptor (VNR) permit the exploration of the role of these two receptors in focal contact formation. Singer and coworkers (1988) have recently investigated the distribution of VNR and FNR in human fibroblasts and melanoma cells cultured on different substrata. When these cells were plated in the presence of serum, both receptors were initially codistributed in the focal contacts. However, with time there was a redistribution of the FNR to sites of adhesion to FNcontaining bundles, while the VNR remained in the focal contacts.

In this paper we have explored the behaviour of the FNR and VNR in a human endothelium-derived cell line plated on different substrata. In contrast with the results of Singer et al. (1988), we find that in the presence of serum only the VNR is concentrated in the focal contacts. We also show that on FN-coated coverslips, initially the FNR is prominent in focal contacts whereas the VNR is absent. Within a few hours, however, there is a progressive development of new adhesions expressing the VNR and a decrease in adhesions containing the FNR, even though $F N$ remains extensively spread on the substratum. In contrast, on VN-coated coverslips over a period of $37 \mathrm{~h}$ only the VNR was detected in focal contacts. In addition, we show that focal contacts expressing either the FNR or the VNR are both able to support stress fibres and contain typical focal contact proteins such as talin and vinculin.

After completing this work we received a copy of a manuscript describing the distribution of the VNR and FNR in endothelial cells plated on different ECM substrata (Dejana et al. 1988).

\section{Materials and methods}

\section{Cell culture}

The cells used were a human endothelium-derived line called
EA hy 926 (EA) (Edgell et al. 1983), which expressed von Willebrand Factor as detected by immunofluorescence (data not shown). Cells were normally grown in Dulbecco's modified Eagle's medium containing $10 \%$ foetal calf serum (FCS) and supplemented with penicillin and streptomycin. Serum-free cultures were established by washing suspended cells at least twice in serum-free media before dispersing onto coverslips.

\section{Antibodies and proteins}

The rabbit polyclonal antibody (N681) directed against talin was prepared by repeated immunization with purified human platelet talin, using both native protein as well as material eluted from preparative SDS-polyacrylamide gels. The antiserum has been used to stain the focal contacts of many cell types and was found to stain a single high molecular weight band on Western blots of these cells (our unpublished observations). Before using the antisera to study the distribution of talin in EA cells, we characterized its immuno-specificity by immunoblotting (Fig. 1). The rabbit polyclonal antibody recognizing fibronectin was a generous gift from L. B. Chen (Chen et al. 1976). The monoclonal antibody LM609, which recognizes the VN receptor $\alpha / \beta$ complex, was a generous gift from Dr David Cheresh (Cheresh, 1987). The polyclonal antibody raised against the hamster FN receptor was kindly provided by $\mathrm{Dr}$ R. Juliano (Brown \& Juliano, 1986).

Glass coverslips were coated with $40 \mu \mathrm{g} \mathrm{ml}^{-1}$ purified human plasma fibronectın (New York Blood Center) in PBS or $40 \mu \mathrm{g} \mathrm{ml}^{-1}$ purified human vitronectin (Calbiochem) in PBS for $1-3 \mathrm{~h}$ at $37^{\circ} \mathrm{C}$. The coated coverslips were rinsed in PBS, then transferred to the cell culture media.

\section{$S D S$-polyacrylamide gel electrophoresis (SDS-PAGE) and immunoblotting}

SDS-PAGE was performed in slab gels using the buffer system of Laemmli (1970). Gels contained $10 \%$ acrylamide and $0.13 \%$ bisacrylamide and were immunoblotted as described (Tidball et al. 1986).

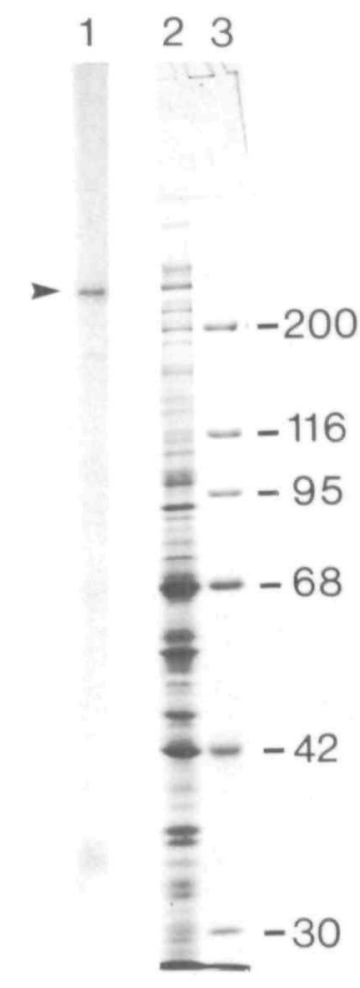

Fig. 1. Talin antibody characterization. Lane 1: a Western blot autoradiograph of total EA hy 926 proteins electrophoresed on a $10 \%$ SDS-polyacrylamide gel and transferred to nitrocellulose. The blot was probed with rabbit polyclonal antiserum directed against mammalian platelet talin (see Materials and methods) followed by a ${ }^{125}$ I-labelled antibody recognuzing rabbit IgG. The immunoblot shows a single reactive band (arrowhead) with a molecular weight of about 230000 , corresponding to talin. Lane 2: a Coomassie Bluestained gel of an equivalent sample to that in lane 1. Lane 3: molecular weight markers $\left(\times 10^{-3}\right)$ : myosin heavy chain (200), $\beta$-galactosidase (116), phosphorylase $b(95)$, bovine serum albumin (68), ovalbumin (42), and carbonic anhydrase (30). 


\section{Indirect immunofluorescence}

Cells on glass coverslips were rinsed with PBS and fixed in $3.7 \%$ formaldehyde in PBS for $10 \mathrm{~min}$ at room temperature. The cells were permeabilized with $0.2 \%$ Triton X-100 in Trisbuffered saline (TBS: $50 \mathrm{~mm}$-Tris $\cdot \mathrm{HCl}, 150 \mathrm{~mm}-\mathrm{NaCl}, 0.1 \%$ $\mathrm{NaN}_{3}, \mathrm{pH} 7.6$ ) for $3 \mathrm{~min}$. Cells were stained with the primary antibody diluted in TBS for $1 \mathrm{~h}$ at $37^{\circ} \mathrm{C}$, rinsed in TBS and stained with a $1 / 50$ dilution of the appropriate secondary antibody. The secondary antibodies used were: FITC-goat anti-mouse IgG ( $\mathrm{H} \& \mathrm{~L}$ chain specific; Cappel), affinity-purified and cross-species adsorbed RITC-donkey anti-rabbit IgG (Chemicon), and FITC-donkey anti-goat IgG (H\&L chain specific; Jackson Immunoresearch lab). For double-label studies, cells were simultaneously stained with a mixture of the primary antibodies, rinsed, and simultaneously stained with a mixture of the fluorescent secondary antibodies. Polymerized actin was stained with $6.6 \mu \mathrm{M}$-rhodamine-phalloidın (Molecular Probes). Note that the EA cells contained a pronounced perinuclear mound, which appeared bright when stained indirectly with all antibodies. The coverslips were viewed on a Zeiss IM 35 microscope equipped with epifluorescence optics. Fluorescence micrographs were photographed at EI 1600 on T-Max 400 and developed with T-Max developer (Kodak).

\section{Results}

Accumulation of VNR and FNR in focal contacts

Cells of a human endothelium-derived line (EA) were plated in serum-free medium on glass coverslips that had
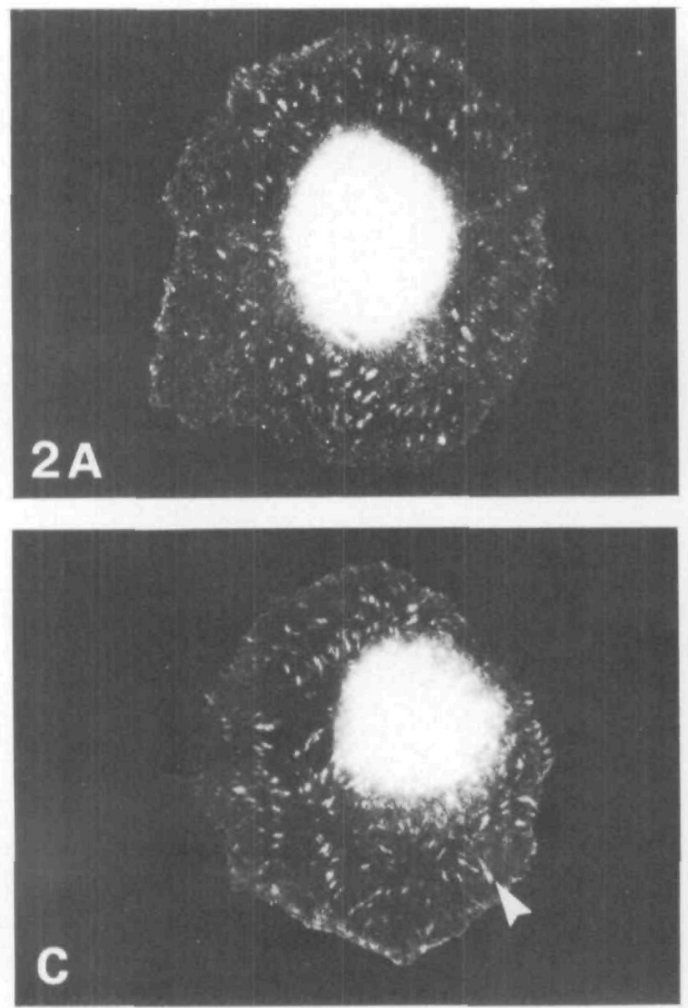

been coated with purified human FN. The cells spread and accumulated FNR in their focal contacts by $1 \mathrm{~h}$ as detected by immunofluorescence (Fig. 2A,C). These adhesions also contained talin (Fig. 2B) and vinculin (not shown), and were associated with the termini of actincontaining stress fibres (Fig. 2D). The stress fibres in these cells were often less pronounced when compared with those in fibroblasts. In many cells there were circumferential bundles of actin filaments, which did not terminate in focal contacts.

Similarly, when EA cells were grown on substrata coated with purified human VN in serum-free medium, the cells formed focal contacts containing the VNR (Fig. 3A,C) as well as talin (Fig. 3B) and vinculin (not shown), and these adhesions were associated with the ends of stress fibres (Fig. 3D). The VNR adhesions were often more round or comma-shaped than the thinner FNR adhesions that developed on FN (cf. Fig. 2 with Fig. 3).

\section{FNR and VNR clustering at focal contacts is specified} by the substratum

To determine the relationship of the FNR and VNR to the substratum, EA cells were plated on either purified FN or VN in serum-free media and double-labelled for VNR and FNR. On FN substrata, the FNR accumulated in focal contacts but the VNR was diffusely distributed (Fig. 4A,B). Conversely, when the cells were plated on
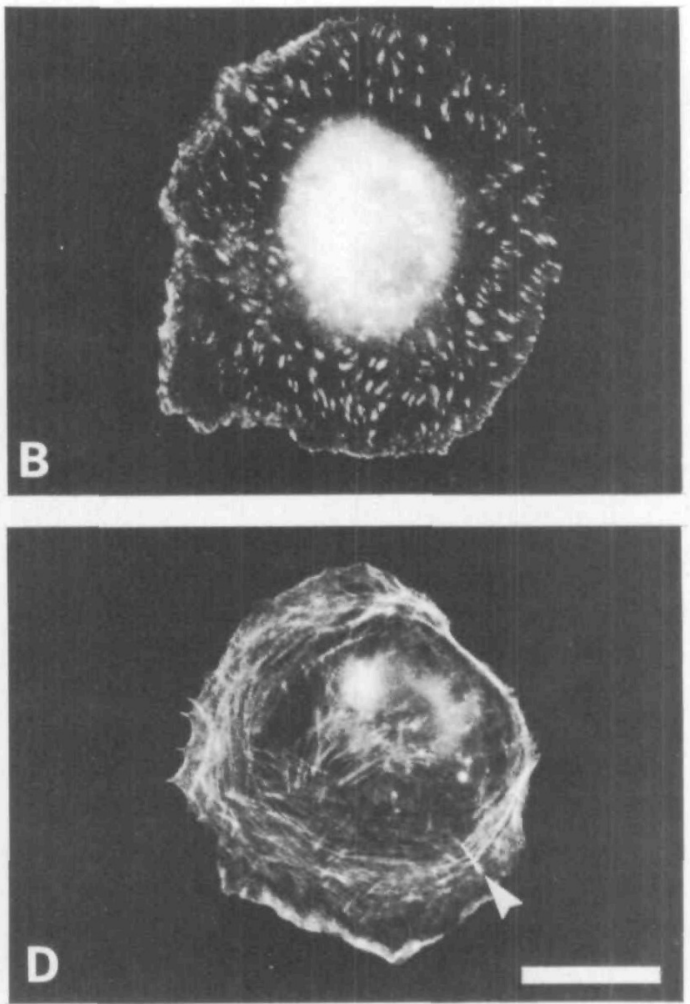

Fig. 2. Localization of FNR in cell adhesions to FN-coated substrata. EA cells were cultured for $1 \mathrm{~h}$ on FN-coated coverslips in serum-free medium, then double-labelled for FNR and talin (A,B) or FNR and actin (C,D). On FN substrata the FNR (A) is concentrated in focal contacts that also contain talin (B). These FNR adhesions (C) can also support stress fibre terminations (arrowheads in C,D) as seen by rhodamine-phalloidin staning. Note that EA cells contain many circumferential actin-filament bundles. Bar, $20 \mu \mathrm{m}$. 

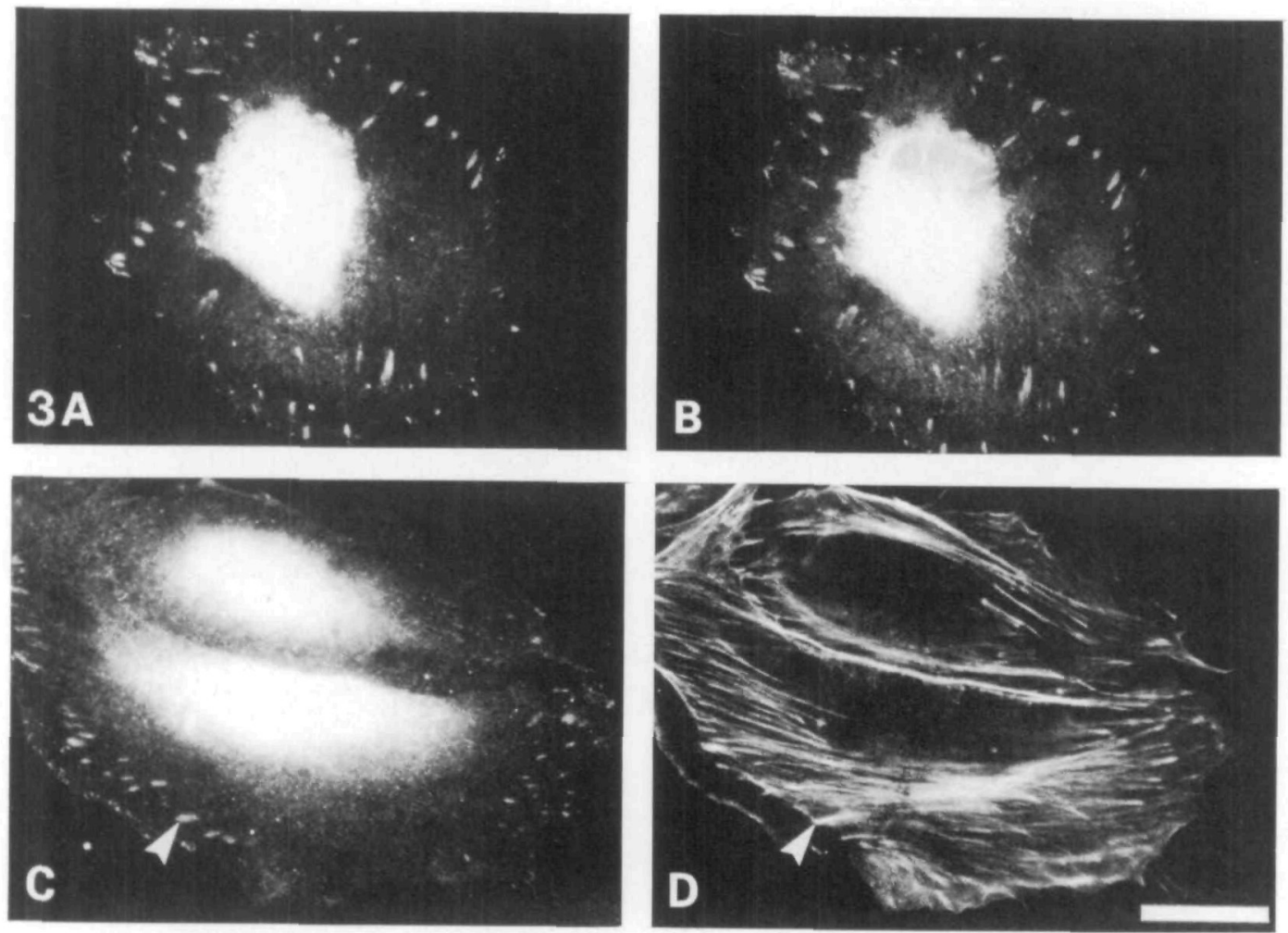

Fig. 3. Localization of VNR in focal contacts on VN-coated substrata. EA cells were cultured for $1 \mathrm{~h}$ on VN-coated coverslips in serum-free medium, then double-labelled for VNR and talin (A,B) or VNR and actin (C,D). Note the extensive co-localization of VNR (A) and talin (B) in focal contacts. The VNR-containing focal contacts (C) were also associated with the ends of stress fibres stained with rhodamine-phalloidin (D). The arrowheads in $C$ and $D$ indicate a stress fibre that terminates in a VNR-containing focal contact. Bar, $20 \mu \mathrm{m}$.

coverslips coated with purified VN, the VNR was concentrated in the focal contacts but the FNR was diffuse (Fig. 4C,D). These results suggest that accumulation of the specific integrins in focal contacts depends on the composition of the substratum.

\section{EA cells plated in senum-containing media form VNR focal contacts}

Having shown that the EA cells can assemble focal contacts containing either the FNR or VNR when plated on purified substrata, we sought to determine which receptor would be assembled into contacts when the cells were plated in normal cell culture conditions with serum present. In these experiments, EA cells were plated on uncoated glass coverslips in medium supplemented with serum (10\% FCS). As shown in Fig. 4 (E,F), cells adhering to serum-coated coverslips formed VNR adhesions that lacked the FNR. The FNR was diffusely distributed throughout the cell. These adhesions also accumulated talin and vinculin, and were associated with stress fibre termini (data not shown). These results suggest that in normal culture conditions (i.e. in medium supplemented with serum), the VNR is the predominant integrin in substratum adhesions formed by these cells.

In the presence of serum, EA cells on FN substrata switch from FNR to VNR in their focal contacts

The above results, combined with the finding that cells can clear FN adsorbed to coverslips (our unpublished results; Avnur \& Gerger, 1981; Grinnell, 1986), suggested that the EA cells might prefer serum VN over substratum-attached $\mathrm{FN}$ when forming focal contacts. We tested this hypothesis by plating cells on FN-coated substrata in serum-containing medium. EA cells were plated on purified human $\mathrm{FN}$ in media containing $10 \%$ FCS and stained for FNR and VNR receptors following $1,3 \cdot 5,6,12,24,37 \mathrm{~h}$ in culture. As shown in Fig. 5 $(A, B)$, the cells initially formed focal contacts similar to those on FN in serum-free media. These adhesions accumulated the FNR but not the VNR, which was diffusely distributed in these cells. After several hours, however, there was a major reorganization of the focal contacts (Fig. 5C-F). Focal contacts containing VNR and generally lacking the FNR began forming at the cell periphery. Some FNR adhesions remained in many cells, but these were usually more centrally located. Moreover, the FNR adhesions tended to become more fibrillar (see below). After $12 \mathrm{~h}$, a majority of cells contained only VNR adhesions and the FNR was diffuse. This complete switch in the integrins expressed in focal contacts was detected in some cells as early as $6 \mathrm{~h}$ after plating (Fig. 5G,H).

In order to determine if the fibrillar pattern of the FNR that develops with time in culture was a result of association with FN fibrils, EA cells were plated on FN substrata and double-labelled for FN and FNR. In 

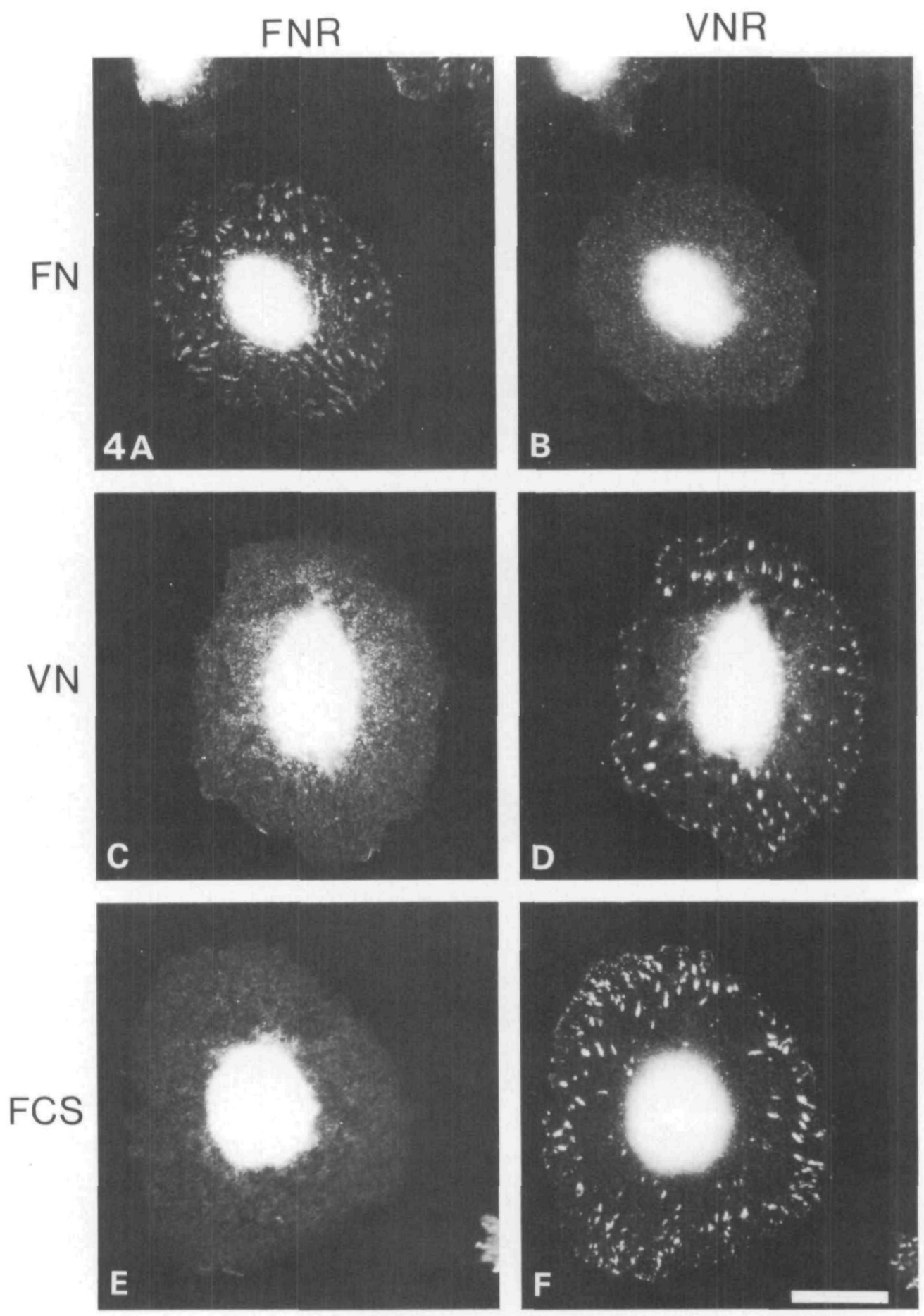

Fig. 4. Double-labelling of VNR and FNR distribution on different substrata. EA cells were plated in serum-free media on glass coverslips that had previously been coated with purified fibronectin (A,B), vitronectin (C,D), or on uncoated coverslips in media containing $10 \%$ foetal calf serum $(E, F)$. The cells were cultured for $1 \mathrm{~h}$, then fixed and double-labelled for VNR and FNR. On FN substrata the FNR (A) but not VNR (B) is concentrated in focal contacts. Conversely, on purified VN substrata the VNR is concentrated in focal contacts (D) while the FNR is diffuse (C). Cells plated on previously uncoated coverslips in the presence of serum contain VNR (F) but not FNR (E) in focal contacts. Bar, $20 \mu \mathrm{m}$.

comparison with many fibroblastic cells, the EA cells did not clear FN extensively from the substratum, although they did assemble small bundles of FN on the ventral surface. The FNR coincided with these FN fibrils (e.g. arrows in Fig. 6A,B). There was also another staining pattern in which the FNR was concentrated in focal contacts that failed to stain along their entire length for FN (see arrows in Fig. 6C,D). The apparent absence of FN from these areas may be due to clearing of the FN, although it is surprising that the FNR remains at these sites without FN. Alternatively, FN may be present at these regions but inaccessible to the $\mathrm{FN}$ antibody because 
FNR
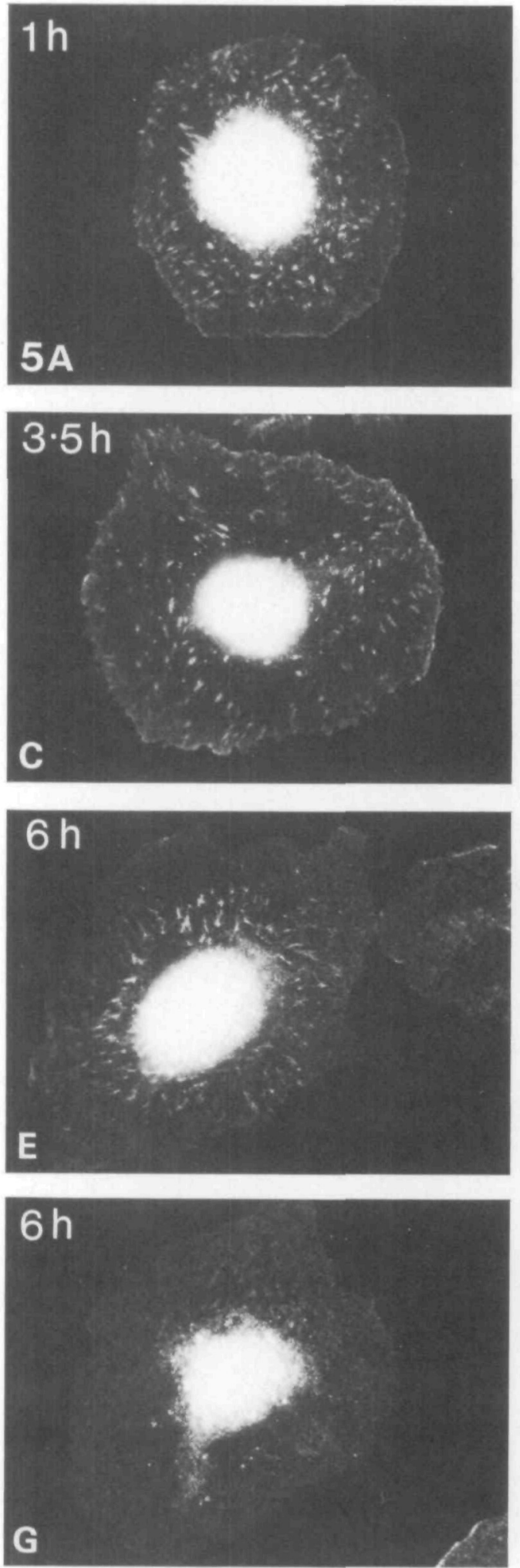
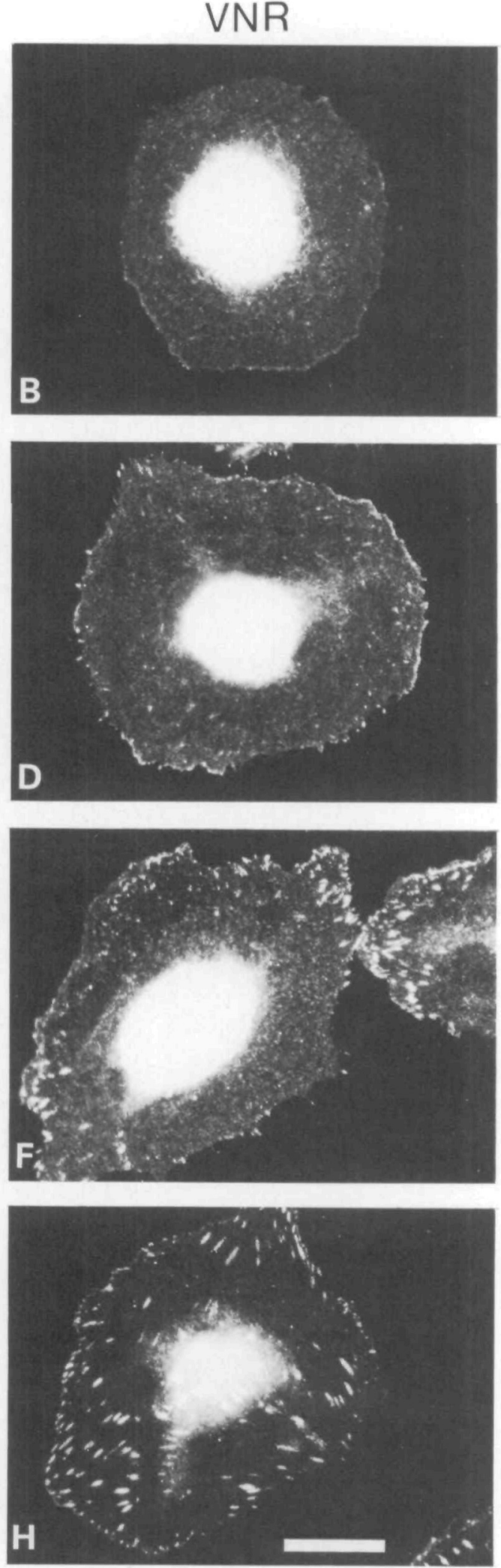

Fig. 5. Cells plated in $10 \%$ FCS on FN-coated coverslips switch from FNR-to VNR-containing adhesions. EA cells were seeded on coverslips coated with FN in serum-containing media and double-labelled for FNR and VNR at $1 \mathrm{~h}(\mathrm{~A}, \mathrm{~B}), 3 \cdot 5 \mathrm{~h}$ (C,D) or $6 \mathrm{~h}(\mathrm{E}-\mathrm{H})$ after plating. At $1 \mathrm{~h}$ the FNR (A) but not VNR (B) was concentrated in focal contacts. By $3-4 \mathrm{~h}$ the FNR (C) was of ten located in central, fibrillar adhesions, while the VNR (D) began to accumulate in peripheral contacts. The fibrillar FNR distribution is more pronounced at $6 \mathrm{~h}(\mathrm{E})$ and the VNR is predominant in peripheral focal contacts $(\mathrm{F})$. Many cells by $6 \mathrm{~h}$, and more markedly by $12 \mathrm{~h}$ (not shown), contain only VNR adhesions (H) whereas the FNR (G) is diffusely distributed. Bar, $20 \mu \mathrm{m}$. 

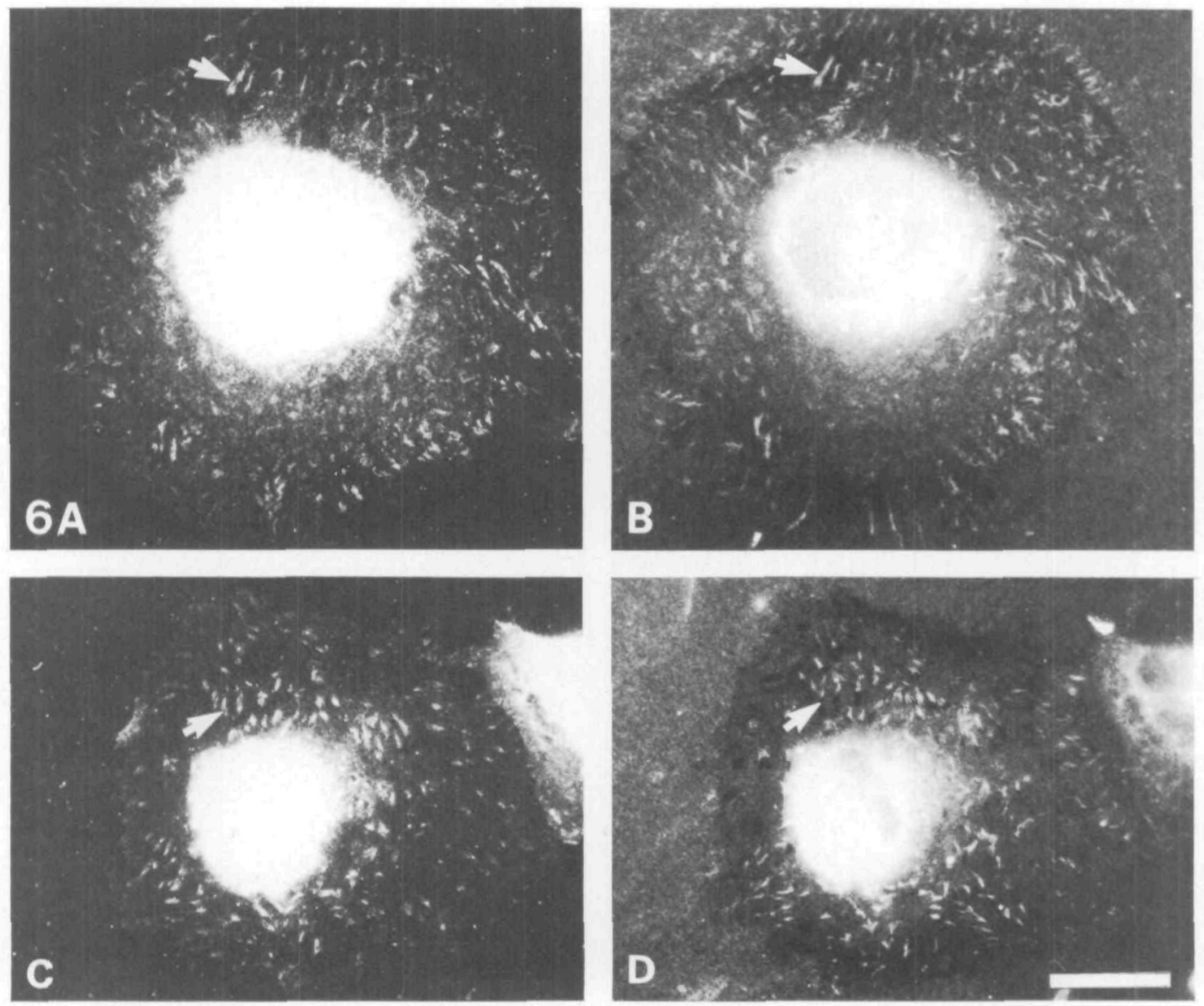

Fig. 6. Association of FNR with FN fibrils. EA cells were cultured on FN-coated substrata in medium containing $10 \%$ FCS for $3.5 \mathrm{~h}$, then double-labelled for FNR $(A, C)$ or for fibronectin (B,D). In A,B the arrows mark an accumulation of FNR (A) that co-localizes with FN fibrils (B). In C,D the arrows indicate the association of FNR (C) with focal contacts that do not stain with the FN antibody along their entire length (D). Bar, $20 \mu \mathrm{m}$.

of the tight substratum adhesion.

The above results showed that EA cells plated on FN can switch from FNR- to VNR-containing adhesions when supplied with media containing soluble VN. We wanted to determine if cells on VN substrata develop focal contacts containing FNR when grown in the presence of serum. EA cells were plated in media containing $10 \% \mathrm{FCS}$ on glass coverslips that had been coated with purified human vitronectin. The cells formed adhesions throughout the entire ventral cell surface containing VNR, but the FNR was diffuse. Only the VNR was observed in cells examined at $1,3 \cdot 5,6,12,24$, $37 \mathrm{~h}$ after plating (data not shown).

\section{Discussion}

In this study we have examined the behaviour of two members of the integrin family of ECM receptors, the fibronectin receptor and the vitronectin receptor, and their relationship to focal contacts formed on different substrata by an endothelium-derived cell type. Our first conclusion is that both receptors can be concentrated in focal contacts depending on the composition of the substratum: cells plated on a VN-coated substratum contain the VNR but no FNR in their focal contacts, whereas cells plated on FN initially contain only the FNR in their focal contacts. Most cells grown in tissue culture are plated in the presence of serum and not on specially prepared substrata. Because both FN and VN are present in serum and both promote adhesion, we wanted to determine which integrin would be present in the focal contacts of cells plated in serum. Under these conditions, we found that the EA cells only expressed the VNR in their focal contacts. It should be noted that $F N$ was present in this serum and was detected on the substratum by immunofluorescence microscopy (data not shown). This absence of the FNR from focal contacts formed in the presence of serum differs from the recent finding of Singer et al. (1988), who found that human fibroblasts and melanoma cells express both receptors in their focal contacts when plated in serum. However, they found that with time the FNR became redistributed away from focal contacts as bundles of $\mathrm{FN}$ were assembled, so that mature focal contacts expressed only the VNR. Both studies lead to the same conclusion regarding mature focal contacts formed in the presence of serum: these adhesions predominantly involve the VNR. This conclusion is consistent with previous observations of the ECM components. In the presence of serum, $\mathrm{FN}$ tends to be cleared from 
focal contacts (Avnur \& Geiger, 1981) whereas VN remains adsorbed to the substratum (Baetscher et al. 1986; Neyfakh et al. 1983). Moreover, FN is generally absent from contacts of cells grown in serum, suggesting that some other ECM component is responsible for formation of these adhesions.

Because the VNR is concentrated in focal contacts formed by cells in the presence of serum, we wanted to determine what occurred when cells were plated on FN. coated substrata, but in the presence of serum. That is to say, would the cells prefer the adsorbed FN or the soluble VN when forming new adhesions? The results of these experiments were quite striking. The focal contacts that formed first were entirely of the FNR type, but with time new focal contacts developed that contained the VNR. These new contacts were first detected at the cell periphery, the region where focal contacts have been shown to develop (Bershadsky et al. 1985; DePasquale \& Izzard, 1987; Izzard \& Lochner, 1980). After approximately $6 \mathrm{~h}$ in culture, some cell adhesions contained only the VNR, although many cells exhibited focal contacts containing either the VNR or the FNR. Only occasionally did we observe single focal contacts containing a mixture of both receptors. In cells showing two types of focal contacts, generally the VNR adhesions were peripheral while the FNR adhesions were more perinuclear. These latter focal contacts were often more linear and elongated, due in part to the formation of small bundles of FN on the ventral surface. Compared with many cells, however, these EA cells do not clear a substantial amount of the adsorbed FN and only assemble the FN into small fibrils. These cells secrete little, if any, FN (data not illustrated). Some cells retained the FNR associated with the FN-containing fibrils for prolonged periods $(37 \mathrm{~h}$ was the longest time point examined), but from $12 \mathrm{~h}$ onwards most cells had focal contacts that contained only the VNR. Examining the ECM components on the substratum revealed that both $\mathrm{FN}$ from the initial coating as well as VN adsorbed from the serum were present. This leads us to conclude that, for these cells in the presence of serum, VN is the preferred ECM substratum and the VNR is the integrin normally concentrated in focal contacts.

A major objective in this research area has been to determine how stress fibres are attached to the plasma membrane at the focal contact. The integrins may have a major role as transmembrane receptors linking the extracellular ECM to the intracellular cytoskeleton. A potential interaction between integrins and the cytoskeletal protein talin has been demonstrated in vitro using the avian form of integrin and talin (Horwitz et al. 1986). We have suggested that focal contacts containing different integrins can support the same cytoskeletal proteins (Burridge et al. 1988). Our data are consistent with this idea. Focal contacts containing either the FNR or the VNR support stress fibres and concentrate typical focal contact proteins such as talin and vinculin. Sequence analysis of various cloned integrins, including the mammalian FNR and VNR, reveals considerable homology in the cytoplasmic domains of these receptors, particularly for the $\beta$ chains (Argraves et al. 1987; Fitzgerald et al.
1987). This observation, together with the finding that either the FNR or VNR can support an equivalent repertoire of cytoskeletal proteins, leads us to suggest that the cell does not discriminate between VN or FN (and possibly other ECM components) when assembling stress fibres at focal contacts. Different integrins will be recruited to the focal contacts, depending on the ECM component adsorbed to the substratum, but because of their similar cytoplasmic domains these different integrins will, in turn, recruit the same set of cytoskeletal proteins at the cytoplasmic face of the focal contact.

We thank Drs David Cheresh and R. Juliano for providing us with the monoclonal anti-vitronectin receptor and the polyclonal anti-fibronectin receptor antibodies, respectively. We greatly appreciate the advice and comments of Dr Carol Otey, Dr Leslie Molony and Mr William Griffiths. We also thank Drs I. I. Singer and P. C. Marchisio for sending us copies of their manuscripts before publication. Work was supported by a grant to K.B. from NIH (GM29860) and a grant to C.-J.E. from NIH (HL37653). K.F. was supported by a Muscular Dystrophy Association Postdoctoral Fellowship.

\section{References}

Argraves, W. S., Suzuki, S., Arai, H., Thompson, K., Pierschaacher, M. D. \& Ruoslahti, E. (1987). Amino acid sequence of the human fibronectin receptor. F. Cell Biol. 105, $1183-1190$.

Avnur, Z. \& Geiger, B. (1981). The removal of extracellular fibronectin from areas of cell-substrate contact. Cell 25, 121-132.

BAetscher, M., Pumplin, D. W. \& Bloch, R. J. (1986). Vitronectin at sites of cell-substrate contact in cultures of rat myotubes. $\mathcal{Y}$. Cell Biol. 103, 369-378.

Bershadsky, A. D., Tint, T. S., Neyfakh, A. A. \& Vasiliev, J. M. (1985). Focal contacts of normal and RSV-transformed quail cells. Expl Cell Res. 158, 433-444.

Brown, P. J \& Juliano, R. T. (1985). Selective inhibition of fibronectin-mediated cell adhesion by monoclonal antibodies to a cell surface glycoprotein. Science 228, 1448-1451.

Brown, P. J. \& Jullano, R. T. (1986). Expression and function of a putative cell surface receptor for fibronectin in hamster and human cell lines, J. Cell Biol. 103, 1595-1603.

Buck, C. A. \& Horwitz, A. F. (1987a). Cell surface receptors for extracellular matrix molecules. A. Rev Cell Biol. 3, 179-205.

Buck, C. A. \& HoRwITZ, A. F. (1987b). Integrin, a transmembrane glycoprotein complex mediating cell-substratum adhesion. $\mathcal{Y}$. Cell Sci. Suppl. 8, 231-250.

BURRIDoE, $\mathbf{K}$. (1986). Substrate adhesions in normal and transformed fibroblasts: Organization and regulation of cytoskeletal, membrane and extracellular matrix components at focal contacts. Cancer Rev. 4, 18-78.

Burridge, K., Fath, K., Kelly, T., Nuckolls, G. \& Turner, C. (1988). Focal adhesions: Transmembrane junctions between the extracellular matrix and the cytoskeleton. A. Rev. Cell Biol. 4, 487-525.

Chen, L. B., Gallimore, P. H. \& McDougall, J. K. (1976). Correlation between tumor induction and cell surface LETS protein. Prac. natn. Acad. Sci. U.S.A. 73, 3570-3574.

Chen, W.-T., Hasegawa, E., Hasegawa, T., Weinstock, C. \& YAMADA, K. (1985). Development of cell surface lınkage complexes in cultured fibroblasts. 7. Cell Biol. 100, 1103-1114.

Cheresh, D. A. (1987). Human endothelial cells synthesize and express an arg-gly-asp-directed adhesion receptor involved in attachment to fibrinogen and von Willebrand factor. Proc. " $a t$ " Acad. Sci. U.S.A. 84, 6471-6475.

Couchman, J. R., Rees, D. A., Green, M. R. \& Smith, C. G. (1982). Fibronectin has a dual role in locomotion and anchorage of primary chick fibroblasts and can promote entry into the division 
cycle. 7. Cell Biol. 93, 402-410.

Damsky, C. H., Knudsen, K. A., Bradley, D., Buck, C. A. \& HorwITZ, A. F. (1985). Distribution of the cell substratum attachment (CSAT) antigen on myogenic and fibroblastic cells in culture. Y. Cell Biol. 100, 1528-1539.

Dejana, E., Colella, S., Conforti, G., Abbadini, M., Gaboli, M. \& Marchisio, P. C. (1988). Fibronectin and vitronectin regulate the organization of therr respective arg-gly-asp adhesion receptors in cultured human endothelial cells. 9. Cell Biol. 107 1215-1223.

DePasquale, J. A. \& Izzard, C. S. (1987). Evidence for an actincontaining cytoplasmic precursor of the focal contact and the tıming of incorporation of vinculin at the focal contact. F. Cell Biol. $105,2803-2809$.

Edgell, C.-J. S., McDonald, C. C. \& Graham, J. B. (1983). Permanent cell line expressing human factor VIII-related antigen established by hybridization. Proc. natn. Acad. Sci. U.S.A. 80, 3734-3737.

Fitzgerald, L. A., Steiner, B., Rall, S. C. JR, Lo, S.-S. \& PhiLlips, D. R. (1987). Protein sequence of endothelial glycoprotein IIIa derıved from a cDNA clone. 7. biol. Chem. 262, 3936-3939.

GiancotTI, F. G., Comoglio, P. M. \& TARone, G. (1986). A 135,000 molecular weight plasma membrane glycoprotein involved in fibronectın-mediated cell adhesion. Expl Cell Res. 163, 47-62.

Greve, J. M. \& Gotrlieb, D. I. (1982). Monoclonal antibodies which alter the morphology of cultured chick myogenic cells. J. Cell Biochem. 18, 221-229.

GrinNelL, F. (1986). Focal adhesion sites and the removal of substratum-bound fibronectin. Y. Cell Biol. 103, 2697-2706.

Hayman, E. G., Pierschiacher, M. D. \& Ruoslahti, E. (1985a). Detachment of cells from culture substrate by soluble fibronectin peptides. F. Cell Biol. 100, 1948-1954.

Hayman, E. G., Pierschbacher, M. D., Suzuki, S. \& Ruoslahti, E. (1985b). Vitronectin - A major cell attachment-promoting protein in fetal bovine serum. Expl Cell Res 160, 245-258.

Horwitz, A., Duggan, K., Buck, C., Beckerle, M. \& Burridge, K. (1986). Interaction of plasma membrane fibronectin receptor with talin - a transmembrane linkage. Nature, Lond. 320, 531-533.

HYNES, R. O. (1987). Integrins, A family of cell surface receptors. Cell 48, 549-554.

IzZARD, C. S. \& LoChNER, L. R. (1976). Cell-to-substrate contacts in living fibroblasts: an interference reflexion study with an evaluation of the technique. F. Cell Sci. 21, 129-159.

IzZARD, C. S. \& LoCHNER, L. R. (1980). Formation of cell-to- substrate contacts during fibroblast motılity: an interference reflexion study. F. Cell Sci. 42, 81-116.

Kelly, T., Molony, L. \& Burridge, K. (1987). Purification of two smooth muscle glycoproteins related to integrin: distribution in cultured chicken embryo fibroblasts. F. biol. Chem. 262, $17189-17199$

LAEMMLI, U. K. (1970). Cleavage of structural proteins during assembly of the head of bacteriophage T4. Nature, Lond. 227 , 680-685.

Marcantonio, E. E. \& Hynes, R. O. (1988). Antibodies to the conserved cytoplasmic domain of the integrin $\beta_{1}$ subunit react with proteins in vertebrates, invertebrates and fungi. 7 . Cell Biol. 106, $1765-1772$.

Neff, N. T., Lowrey, C., Decker, C., Tovar, A., Damsky, C., Buck, C. \& HorwITZ, A. F. (1982). A monoclonal antibody detaches embryonic skeletal muscle from extracellular natrices. 7. Cell Biol. 95, 654-666.

Neyfakh, A. A. Jr, Tint, I. S., SvtTkina, T. M., Bershadsky, A. D. \& GELFAND, V. I. (1983). Visualization of cellular focal contacts using a monoclonal antibody to $80 \mathrm{kD}$ serum protein adsorbed on the substratum. Expl Cell Res. 149, 387-396.

Pierschbacher, M. D., Hayman, E. G. \& Ruoslahti, E. (1983). Synthetic peptide with cell attachment activity of fibronectin. Proc. natn. Acad. Sci. U.S.A. 80, 1224-1227.

Ruoslahti, E. \& Pierschbacher, M. D. (1987). New perspectives in cell adhesion: RGD and integrins. Science 238, 491-497.

Singer, I. I., ScotT, S., Kawka, D. W., Kazazis, D. M., GailtT, J. \& RuOSLAHTI, E. (1988). Cell surface distribution of fibronectin and vitronectin receptors depends on substrate composition and extracellular matrix accumulation. J. Cell Biol. 106, 2171-2182.

Tidball, J. G., O'Halloran, T. \& Burridge, K. (1986). Talin at myotendinous junctions. F. Cell Biol. 103, 1465-1472.

Woods, A. \& Couchman, J. R. (1988). Focal adhesions and cellmatrix interactions. Collagen Rel. Res. 8, 155-182.

Woods, A., Couchman, J. R., Johansson, S. \& Hook, M. (1986). Adhesion and cytoskeletal organization of fibroblasts in response to fibronectin fragments. EMBO \}. 5, 665-670.

YAMADA, K. M. \& KenNedY, D. W. (1987). Peptıde inhibitors of fibronectin, laminin, and other adhesion molecules: unique and shared features. J. cell. Physiol. 130, 21-28.

(Received 26 July 1988 - Accepted 30 August 1988) 
